\title{
Zentralvorstandssitzung vom 28. Oktober 2010
}

KVG-Revision - Der Zentralvorstand (ZV) der FMH stimmt der Verordnung über den Risikoausgleich in der Krankenversicherung (VORA) zu und heisst die Anlagevorschriften mit der Ergänzung gut, dass die Kassen ihr Geld nicht in Gesundheits- und Behandlungseinrichtungen anlegen sollen. Den Kostenbeitrag Spital lehnt er ab, weil dieser besonders Frauen trifft.

Revision Tarifstruktur - Die FMH wird auch die Inputs, welche die Tarifdelegierten in den Workshops des Tarifdelegiertentags vom 20. Oktober 2010 gegeben haben, in die Tarifrevision einbringen.

Einschliessungsverordnung / Schutz vor Mikroorganismen - Der ZV heisst die Vernehmlassungsantwort auf die vom BAG präzisierte Einschliessungsverordnung gut, ebenso die Stellungnahme zur Verordnung über den Schutz der Arbeitnehmenden vor der Gefährdung durch Mikroorganismen.

Delegierte für Fragen der MPA - Die FMH hat Dr. med. Adrian Sury zum neuen Präsidenten und Dr. med. Renato Tognina zum neuen Vizepräsidenten der Delegierten für Fragen der Medizinischen Praxisassistentinnen gewählt.
Totalrevision Alkoholgesetz - Der ZV nimmt Stellung zur Totalrevision des Alkoholgesetzes. Hauptkritikpunkte sind die Nicht-Berücksichtigung der Verhältnisprävention und der Marktregulierung sowie die Tatsache, dass gesundheitspolitische Akteure nicht zur Vernehmlassung eingeladen wurden.

Leitbild «Herausforderung Sucht» - Die FMH stimmt dem Leitbild «Herausforderung Sucht» zu. Dieses hat das Ziel, den drei eidgenössischen Kommissionen, die sich mit Suchtfragen auseinandersetzen, eine kohärente Suchtpolitik zu ermöglichen.

Kampagne UNIFEM - Die FMH unterstützt die Informationskampagne «Gewalt an Frauen» der UNIFEM (Schweizerisches Komitee des United Nations Development Fund for Women).

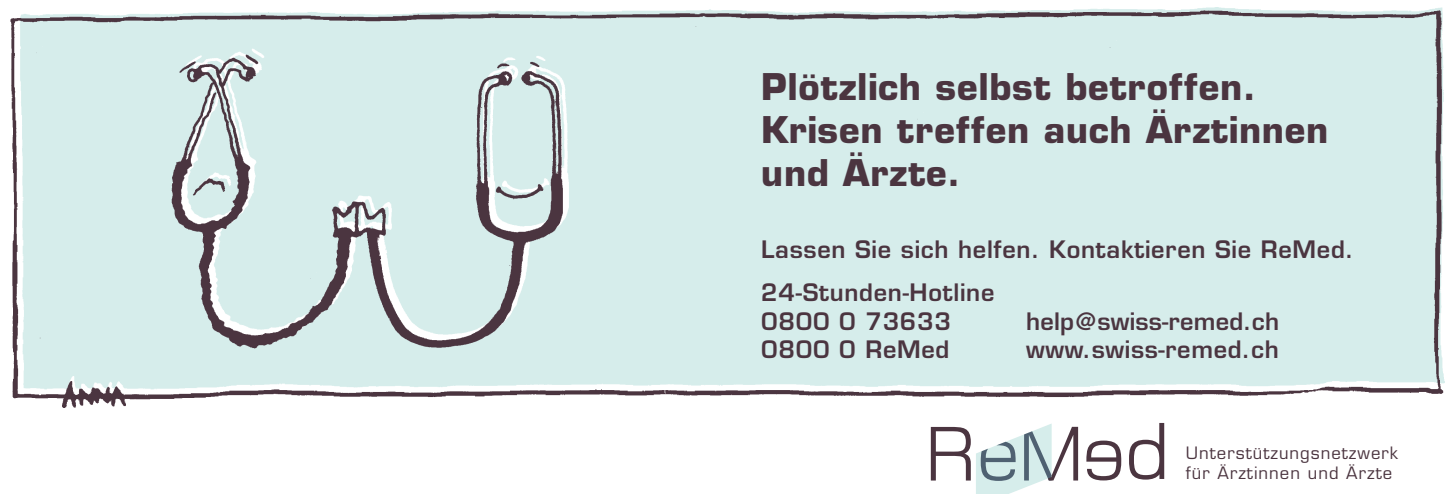

